\title{
Dr Grantly Dick-Read (1890-1959) of Norfolk and natural childbirth
}

\author{
Peter M Dunn
}

The son of a prosperous Norfolk miller, and the sixth of seven children, Grantly Dick-Read was born in Norfolk on 26 January 1890. He was educated at Bishop's Stortford College, and St John's College, Cambridge, moving on to receive his clinical training at the London Hospital where he qualified in 1914. Besides interests in nature, poetry and music (piano and cello), he was a first class all round athlete, boxer, and games player (cricket and football). At the outbreak of war in 1914 he volunteered for service in the RAMC and served in Gallipoli, where he was severely wounded, and later in France. After the war he returned to the London Hospital for a year as resident accoucheur and then, after taking an $\mathrm{MD}$ at Cambridge in 1920, entered general practice, eventually joining a partnership in Woking, Surrey. In 1921 he married Dorothea Cannon by whom he had two sons and two daughters.

Throughout the remainder of his life Dick-Read's consuming preoccupation was with the preparation for and management of normal childbirth. He was concerned at the increasing use of anaesthesia, twilight sleep, and obstetric intervention and also at the neglect of the woman's psyche before and during this profoundly emotional event. These concerns and his own approach were discussed in many publications, the earliest and best known of which were Natural Childbirth $(1933)^{1}$ and Childbirth Without Fear $(1944)^{2}$ from which most of the extracts that follow were taken.

University of Bristol, Southmead Hospital

Correspondence to: Professor P M Dunn Department of Child Health, Southmead Hospital, Southmead Road, Bristol BS10 5NB.

\section{On obstetric intervention and anaesthesia:}

'One of the most important factors in the production of complicated labour and therefore of maternal and infantile morbidity, is the inability of obstetricians and midwives to stand by and allow the natural and uninterrupted course of labour. It may be an excess of zeal, or anxiety born of ignorance, but it is an unquestionable fact that interference is still one of the greatest dangers with which both mother and child have to contend'.

'Nothing is more to be abhorred. The forceps deliveries of normal babies - blue and flabby babies who will not cry, babies drugged and babies anaesthetized, these pictures so common in modern practice are deplorable blunders of both judgment and action'.

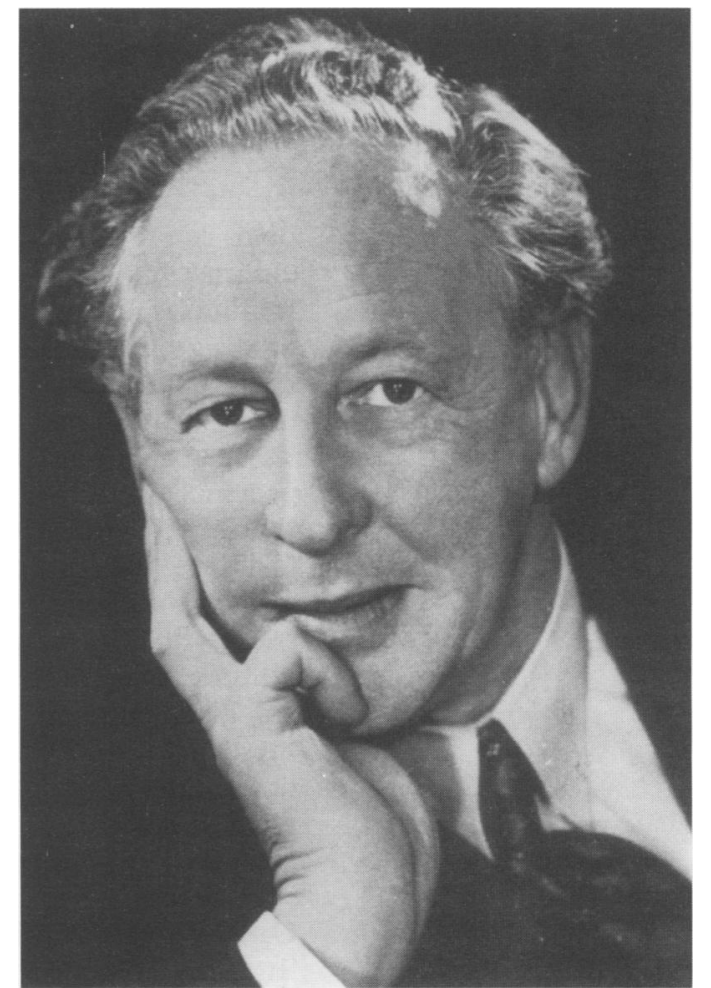

Grantly Dick-Read (1890-1959).

On pain in childbirth:

'Woman ... is adapted primarily for the perfection of womanhood which is, according to the law of Nature, reproduction. All that is most beautiful in her life is associated with the emotions leading up to this ultimate function. But unfortunately in the final perfection of these joys a large majority remember only the pain and anguish and even terror that they were called upon to endure at the birth of their first child. That is indeed a paradox. For generations, childbirth has been accepted as a dangerous and painful experience'.

'Obstetric teaching has made great advances in the use of drugs, analgesics and anaesthetics, but little has been done to investigate the problem of pain from the point of view of its preclusion... Anything that disturbs the confidence and peacefulness of the mother disrupts the neuromuscular harmony of her labour... In childbirth, fear and the anticipation of pain give rise to natural protective tensions in the 
body. Unfortunately, the natural muscular tension produced by fear also influences the muscles that close the womb and thus delay the progress of the labour and create pain... The safest and most effective way to minimise the discomforts of childbirth is to enable a woman, by preparation for, and understanding attention at labour to have her baby naturally... Education and antenatal instruction are important factors in the relief of pain in childbirth...'

'I never left any woman alone during labour, a prey to the destructive forces of uncontrolled imagination. If I could not be there myself from the start, I made sure that someone was with her - her husband, mother, or sister, to whom I had already given a little instruction on what to expect...'

'The vicious circle of the fear-tensionpain syndrome is responsible for the pain of labour. In 90 or 95 per cent of cases, severe pain can be avoided or overcome by the elimination of fear and tension. This minimises but does not preclude the use of drugs and analgesics, but decreases the risks incurred by both mother and child in deep or prolonged narcosis...'

'The fear and pain of childbirth is the province of the obstetric physician whose specialised education and intellectual bent facilitate the understanding of emotional states and sensory disturbances. To be successful he employs mental attributes different from those of the specialised gynaecological surgeon. The incompatibility of these two authoritative vocations makes unanimity difficult upon the subject of pain relief in labour'.

\section{On the wonder of childbirth:}

'It is my custom to lift up the crying child even before the cord is cut so that the mother may see ...the reality of her dreams ...the first to grasp the small fingers and touch gingerly the soft skin of the infant's cheek... Its first cry remains an indelible memory on the mind of a mother... No mother and no child should be denied that great mystical association...it lays a foundation of unity of both body and spirit upon which the whole edifice of mother love stands. Many times I have called attention to the wonderful picture of pure ecstasy that we see at a natural birth... Is it just an accident that the brilliant sunlight of motherhood breaks through and dispels for all time the clouds of her labour? No change in human emotions is more dramatic... Such an aura of beauty has filled the whole atmosphere of the room and such superhuman loveliness has swept over the features of the girl whose baby is crying in her hands... I have experienced a sense of happiness myself much more akin to reverence and awe than to the simple satisfaction of just another natural birth'.

In private life Grantly Dick-Read was delightful company and enjoyed the good things in life. ${ }^{3} \mathrm{He}$ was a man of striking appearance and an enthusiastic and brilliant speaker. $\mathrm{He}$ was also forthright and uncompromising in his views, many of which challenged the established practice of the day. Far ahead of his time, he suffered the fate of many pioneers and was given a hard time by the medical establishment. But there were exceptions, such as F J Browne who invited him in 1936 to contribute to his text, Antenatal and Postnatal Care $^{4}$ and $\mathrm{H}$ Thoms and his team in Yale after the second world war. However, his writings reached a very wide audience and his work was acclaimed by the public a generation before the obstetric world generally recognised its fundamental importance.

In 1948 , finding he could no longer work to his satisfaction in England, and accompanied by his second wife Jessica Bennett, he spent five years practising in Johannesburg before returning slowly by caravan 6000 miles across Africa, studying childbirth practices along the way. He found that well over 90 per cent of women in the tribes he visited had normal, natural births and needed no more convalescence than a few hours' rest. He noted how they automatically adopted an upright position which made passage through the birth canal both safer and easier for the child. He observed that in most tribes the mother was well instructed in the course of labour by old women in whom she had complete confidence and that she was never left alone when in labour. It was particularly interesting to him to see at first hand the profound respect that every tribe had for the afterbirth and the manner of its delivery. Again, any interference with the work of nature was banned. A child was never separated from the placenta until that structure had been delivered. Only then might the cord be cut and the offspring delivered into its mother's embrace. He wrote:

'There will always be abnormalities in all forms of reproduction throughout the realms of nature, but the complications of pathological childbirth are few compared with the man-made troubles that emerge through his failure to understand the simple physiological mechanism and demands... If the wisdom of the primitive African woman was combined with understanding of the white people, the trials and tribulations of childbirth would be reduced to negligible proportions'.

Grantly Dick-Read died in Norfolk on 11 June 1959, aged 69. Although he received no official recognition from the medical profession, he had and still has the profound gratitude of countless mothers throughout the world. His contributions to obstetrics were of historic significance.

1 Dick-Read G. Natural childbirth. London: William Heinemann, 1933

2 Dick-Read G. Childbirth without fear. London: William Heinemann, 1942.

3 Grantly Dick-Read MD [Obituary]. BMF 1959; i: 1625.

4 Browne FJ. Antenatal and postnatal care. London: J and A Churchili, 1936. 